Reprod. Nutr. Dévelop., 1987, 27 (4), 849-857.

\title{
An integrated model for intestinal development in the fetal sheep
}

\author{
J. F. TRAHAIR, P. M. ROBINSON
}

Department of Anatomy, University of Melbourne, Parkville, 3052, Victoria, Australia

Summary. The interrelationships between 22 parameters relating to small intestinal morphology and enterocyte cell kinetics were investigated. It was found that all significant correlations could be related to changes in intestinal diameter.

The area of accessory and mucosal coats in cross section was computed and a constancy of relative composition, independent of experimental perturbation, was noted. It appears likely that despite seemingly trophic responses in specific tissue components, an overall balance of these components is maintained in the developing intestine. The need to develop integrated models of gut structure and function to allow adequate interpretation of results is discussed.

\section{Introduction.}

Elsewhere we have shown that growth and development in utero of most components of the intestinal wall of the sheep takes place in a very orderly manner.

We and others (see Henning, 1985 ; Klein and McKenzie, 1983) have proposed that cortisol might specifically be involved in organizing some of the changes associated with normal development, in particular, late in gestation and soon after birth (Trahair and Robinson, 1986a,b ; Trahair et al., 1986a). This proposal was investigated by early cortisol infusion and bilateral adrenalectomy (ADX) in utero (Trahair et al., 1984 ; 1987a,b). For some observations, notably increases in migration rate of enterocytes and of the proportion of crypt cells labelled after a pulse of tritiated thymidine as a result of early cortisol infusion, and reduction of migration rate after ADX, the changes were in accord with the above proposal. We have also investigated the role of putative trophic factors in amniotic fluid in a series of fetuses where the ingestion of amniotic fluid was prevented (Trahair et al., 1986b). However in all these experiments, and most likely the experiments of other workers, changes in a wider range of parameters have been noted, though these changes may have not reached significant levels within the experimental design. 
While most experiments investigate the effects of various agents, postulating a direct effect on a specific target tissue, it is possible, however, that the changes seen in one parameter or tissue compartment may not be direct but might be the result of a response to the changes in another. In this manner, the tissue components might be able to maintain some predetermined biological equilibrium. Such a relationship may go unnoticed in analyses where only mean sizes of components are compared between the experimental and control groups. An analysis of the interrelated aspects of growth requires that a relatively large data base be available. With our studies such a body of information has become available and is presented for analysis as a whole for the first time.

The present paper therefore analyses the degree of interaction in changes associated with not only normal growth but also with experimental perturbation, thereby providing valuable insight into the nature of growth and maintenance of normal intestinal structure throughout development.

\section{Materials and methods.}

Data presented in this paper were collected from a series of experiments. Results from the following studies were included in this analysis :

i) Morphometric analysis of intestinal growth at 115 days $(n=12)$ and 136 days ( $n=12$ ) gestation (term ca. 147 days) (Trahair et al., 1986a).

ii) Analysis of intestinal cell kinetics in normal development (115 days, $n=11$ ) (136 days, $\mathrm{n}=10$ ) (Trahair et al., 1986c, d).

iii) Morphometric analysis of intestinal growth and intestinal cell kinetics after bilateral adrenalectomy (136 days, $n=10$ ) or cortisol infusion (115 days, $n=10$ ) (Trahair et al., 1987a,b).

iv) Morphometric analysis of the effects of esophageal fistulation (136 days, $\mathrm{n}=4$ ) (Trahair et al., 1986b).

Analysis of size of intestinal components was carried out on paraffin embedded, Bouins fixed tissue, using a Zeiss Videoplan. Briefly, the following parameters were measured (in $\mathrm{mm}$, unless otherwise stated) : intestinal diameter, wall thickness $=$ sum of (external muscle thickness, submucosal thickness, mucosal thickness), villus height, crypt depth, villus cell column count (number of enterocytes along longitudinal villus profile), villus base width, number of villi per $\mathrm{mm}^{2}$, number of crypts per $\mathrm{mm}^{2}$. The number of villi and crypts were estimated per unit length of mucosal tube from the later two parameters. Crypt-villus ratios were calculated both from villus and crypt densities per $\mathrm{mm}^{2}$ and from densities per unit length of tube. The mean annular area in sections of each intestinal wall component was calculated from the mean linear size parameter and expressed as a percentage of the total wall area. No estimates of variance were attempted.

Cell kinetic data were collected from proliferation and migration studies where $\left({ }^{3} \mathrm{H}\right)$ thymidine had been introduced into the fetus prior to sacrifice. Autoradiographs were subsequently prepared and assessed for enterocyte migration. Migration rates were expressed as a percentage of villús height migrated per day, $\mathrm{mm}$ villus height per day, and the number of days for $100 \%$ renewal. 
Details of all methods have been given respectively in each of the publications cited above.

Correlation (Pearson product moment) analysis was performed using the mean value for each parameter for all combinations of complete data sets. Significance was accepted at $p<0.05$.

\section{Results.}

As a first step in this analysis, the area of each wall component was calculated from the mean width of each component, assuming that the intestine was a perfect circle and the area of each component was a regular annulus. No attempt to estimate the variance for these areas was made, especially since it was the relative sizes which were of most interest in the present investigation.

Although the estimate for the areas of each component changed in response to increasing age and experimental perturbation (table 1), examination of the percentage of the total wall area which each component occupied (table 2) revealed that an overall balance of wall components was maintained.

TABLE 1

The calculated area $\left(\mathrm{mm}^{2}\right)$ in cross section for each component of the intestinal wall, assuming the area is a perfect annulus.

$E$ - external muscle ; $S$ - submucosa ; $M$ - mucosa ; $W$ - total wall.

Fetuses at 115 days and 136 days gestation $(115,136)$; cortisol infused, 115 days (CORT) ; bilateral adrenalectomized, 136 days (ADX); and esophageal fistulated, 136 days gestation (ESO) were examined, both proximal and distal small intestine. Note : only means have been used in computation, no estimate of variance has been attempted.

\begin{tabular}{ccccccccccc}
\hline & \multicolumn{3}{c}{ Proximal } & \multicolumn{7}{c}{ Distal } \\
\hline & 115 & 136 & CORT & ADX & ESO & 115 & 136 & CORT & ADX & ESO \\
\hline E & 0.72 & 0.75 & 0.55 & 1.09 & 0.71 & 0.79 & 1.40 & 0.70 & 1.64 & 0.81 \\
S & 0.35 & 0.55 & 0.34 & 0.66 & 0.52 & 0.38 & 0.63 & 0.60 & 1.19 & 0.54 \\
M & 2.26 & 4.56 & 1.73 & 4.93 & 2.80 & 2.56 & 6.39 & 3.54 & 6.04 & 4.29 \\
W & 3.33 & 5.86 & 2.02 & 6.68 & 4.03 & 3.73 & 8.42 & 4.82 & 8.87 & 5.64 \\
\hline
\end{tabular}

TABLE 2

The mean area of each component of the intestinal wall given in Table 1 expressed as a percentage

$1 \%)$ of the total wall $(E+S+M)$ area.

See Table 1 for abbreviations.

Note : No estimate of variance has been attempted.

\begin{tabular}{ccccccccccc}
\hline & \multicolumn{3}{c}{ Proximal } & \multicolumn{9}{c}{ Distal } \\
\hline & 115 & 136 & CORT & ADX & ESO & 115 & 136 & CORT & ADX & ESO \\
\hline E & 22 & 13 & 21 & 16 & 18 & 21 & 17 & 14 & 18 & 14 \\
S & 11 & 9 & 13 & 10 & 13 & 10 & 7 & 12 & 13 & 10 \\
M & 68 & 78 & 66 & 74 & 69 & 69 & 76 & 73 & 68 & 76 \\
\hline
\end{tabular}




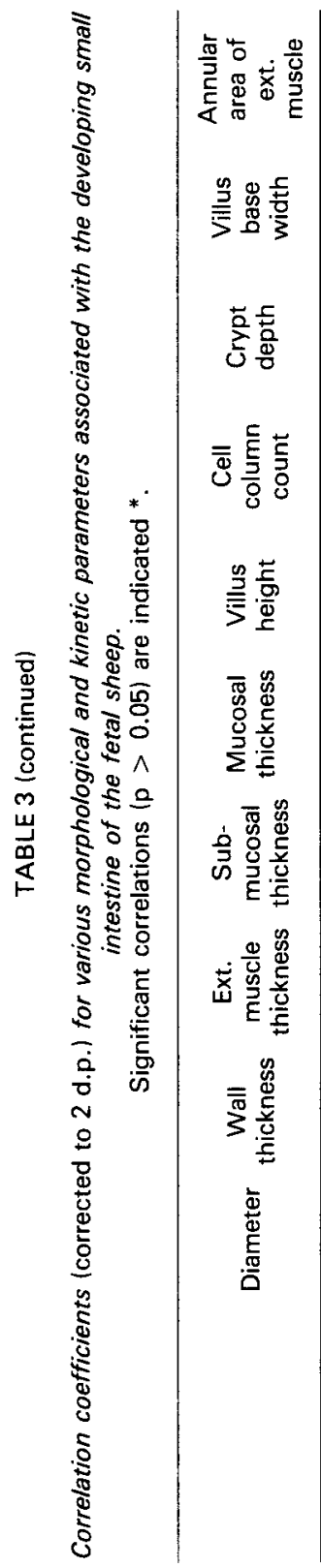

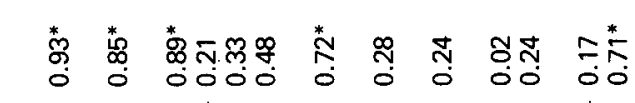

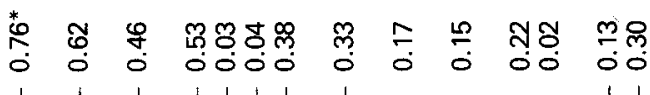

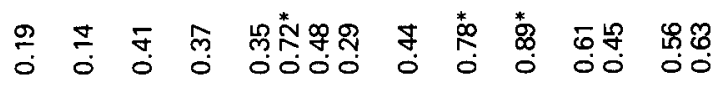

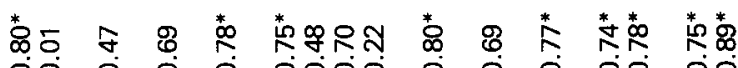
OO 000 DOO० 000000

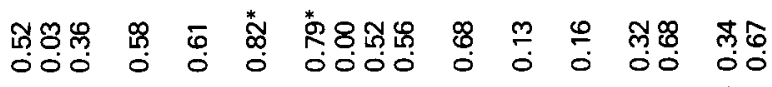

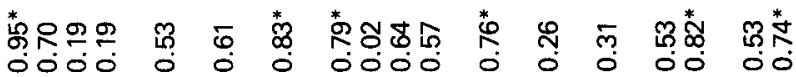

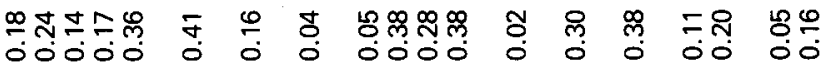
00000 व

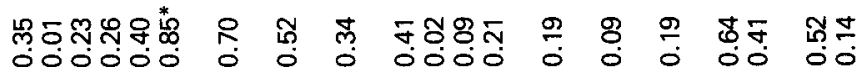

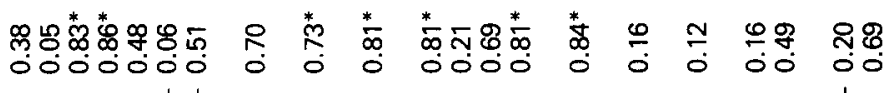

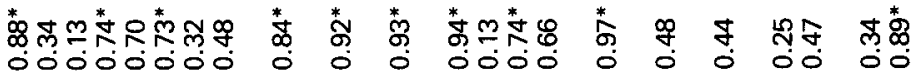
密罗

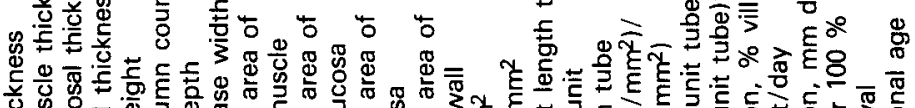

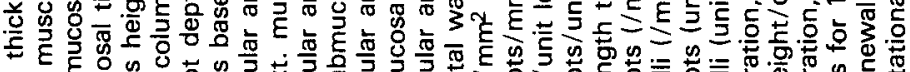

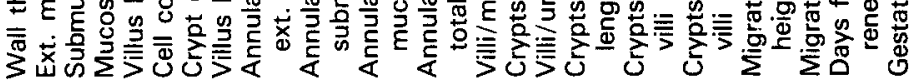




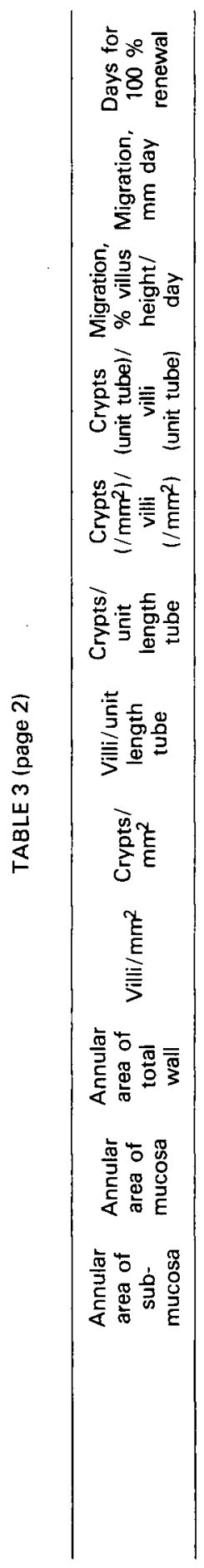

$q$
0
1
0
0

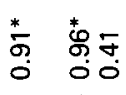

1

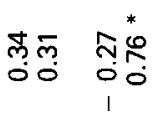

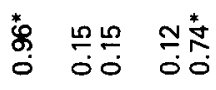

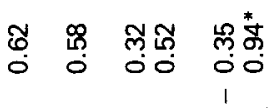

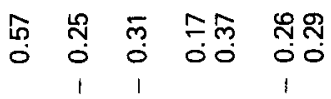

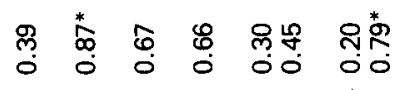

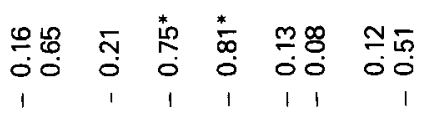

m్ㅠ웡

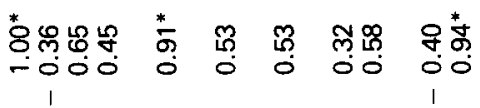

赵

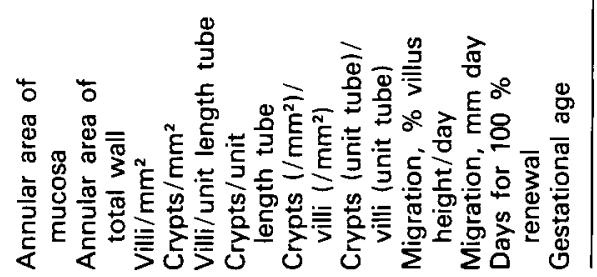

Reproduction, Nutrition, Développement $n^{\circ} 4$, vol. 27 (1987), - 9 
The proportions for each wall component were similar for all groups (all values within 2 s.d. of the mean) although the coefficient of variation was smallest $(6 \%)$ for the mucosal area. The average proportion for the external muscle was $17.4 \%( \pm 3.2$ s.d. $)$, for the submucosa $10.8 \%( \pm 2.0)$, and for the mucosa $71.7 \%( \pm 4.2)$.

The constancy of wall composition suggested that diameter was a major influence on each component of the intestinal wall, such that an overall balance of tissue was maintained. To investigate this proposal and other possible interactions, the degree of correlation between all the parameters measured was investigated. The correlation coefficients for all combinations of the parameters measured are given in Table 3. (Note : Since experiments employing esophageal fistulated fetuses did not include studies of cell kinetics, data from this group has been excluded in the analysis.)

Of the 253 coefficients listed, 64 were statistically significant lat the $95 \%$ confidence level, the correlation coefficient becomes significant at values outside the range \pm 0.71 ). With 253 coefficients, one would expect 18 to be significant by chance (at $95 \%$ confidence) and that their distribution would be random. Thus, there were 3.6 times the number of significant correlations expected by chance alone. Furthermore, they appeared to be non-random. It was noted that all significant correlations could be ultimately related to a significant correlation with diameter, i.e. there was an ordered causal chain of interaction.

An example serves to illustrate this point: renewal time correlated with migration rate (\%/days), which was in turn correlated with migration rate (mm/day), correlated with mucosal thickness, which was either directly correlated with diameter or indirectly correlated with wall thickness, which was correlated with diameter.

\section{Discussion.}

At the outset it should be noted that the finding of a significant degree of correlation cannot be used to prove that a cause and effect situation exists between the two parameters concerned ; observations like this can only lend support to such a suggestion.

The analysis revealed that of those parameters which were interrelated, diameter was correlated to the majority of parameters (including the kinetic parameters) in a non-random manner.

It might be expected that correlation with a large number of variables would occur with a factor which was acting as an important organizer of growth. As such, these results are consistent with a suggestion that the intestinal diameter functions as either a chief organizing element, or the final expression of an organized series of integrated changes, in the model of intestinal growth which we have developed in the sheep fetus.

It should be pointed out however that the present authors do not claim that the analysis summarised in Table 3 is all-encompassing of the total number of parameters which we have presented elsewhere. Notably absent is intestinal 
length which we have examined in a series of normal fetuses (Trahair et al., 1986a). We have not attempted to measure the possible changes to intestinal length in the experimentally altered states reported here since our priorities for tissue use favoured microscopic examination and autoradiographic studies, hence the need for rapid fixation mitigated against the time consuming gross dissection procedures needed to assess length.

Results of this study have indeed shown that the diameter of the intestine has a greater effect on the computed area of a component than the changes which were noted in lengths, heights, thicknesses, or densities. Thus despite specific changes in individual dimensions, the values of the area parameters remained proportionately constant. Such a constancy suggests that the whole tissue may possess a degree of autonomy which is greater than previously thought, a possibility especially important when drawing conclusions as regards the specificity of action of a single factor.

Surprisingly, gestational age was significantly correlated with only 11 of the 22 parameters. The reason for this is most probably because experimental manipulation often has effects on body growth as well, e.g. adrenalectomy retards mucosal growth but brings about an increase in body growth (Trahair et al., 1987a). Thus the age at sacrifice may not very accurately represent the age on a developmental scale.

Changes in these morphometric estimators must also imply changes in the functional status of the intestine, especially with regard to parameters like surface area. It might seem intuitively reasonable to suggest that the various components of the intestinal wall might change in size in parallel with one or several of each other. Changes in one element might either result in, or be the cause of, the more general intestinal changes which were noted.

The shortcomings of other studies to date which have only examined linear morphometric and cell population changes have become evident from the results of this study. Furthermore, the present study emphasizes the need for a comprehensive model to adequately interpret seemingly specific changes in a single parameter. It is entirely possible to demonstrate specific " trophic " responses in a single element, e.g. reduced crypt depth, after experimental perturbation, however, is such a response truly a direct one if diameter has also changed and the overall number of crypts also changed? Many such changes might not be recorded, or, if recorded may never reach significance in a given experimental design. Clearly, a response noted in any single parameter can only be carefully interpreted and its possible significance noted if a model which describes the normal interrelationships exists. In this regard, the recent advances of computer modelling (see Meinzer and Sandblad, 1985) offer a positive solution to the complexities and difficulties which Clarke (1974) referred to when dealing with the problems of the complex architecture and the interpretation of morphometric estimates of size which bedevil studies in intestinal structure and function. In the first instance however, the collection of data as a comprehensive model must precede such numerical and algorithmic investigations. The present study analyses such a body of data for the first time. 


\section{Conclusions.}

Growth of the intestine throughout fetal life is a highly ordered process in which diameter is the chief determinant. This is despite experimentally induced specific changes in putative target tissue components, for example, the mucosal epithelium, found in other studies of the present author, and in studies of others. The authors conclude that a misleading view of intestinal homeostatis can be all too readily gained if an integrated model is not available for critical assessment of the results of experiments.

Reçu en décembre 1986. Accepté en avril 1987.

Résumé. Un modèle intégré du développement de l'intestin chez le fœtus de mouton.

Les interrelations entre 22 paramètres concernant la morphologie de l'intestin grêle et la cinétique de l'entérocyte ont été étudiées. Toutes les corrélations significatives observées peuvent être reliées à des modifications du diamètre de l'intestin.

La surface des couches périphérique et interne de la section transversale a été intégrée et l'on a constaté une constante de la composition relative, indépendante des perturbations expérimentales. II semble probable que malgré des réponses trophiques apparentes dans certains composants tissulaires spécifiques, un équilibre des rapports de ces composants est maintenu au cours du développement de l'intestin. Le besoin de développer des modèles intégrés de la structure et de la fonction de l'intestin pour permettre une interprétation correcte des résultats est discuté.

\section{References}

CLARKE R. M., 1974. Morphological description of intestinal adaptation. Measurements and their meaning. In ROBINSON J. W. L., DOWLING R. H., RIECKEN E. O., Intestinal adaptation. F. K. Schattauer Verlag, Stuttgart, New York.

HENNING S. J., 1985. Ontogeny of enzymes in the small intestine. Ann. Rev. Physiol., 47, 231-245.

KLEIN R. M., MCKENZIE S. C., 1983. The role of cell renewal in the ontogeny of the intestine. II. Regulation of cell proliferation in adult, fetal and neonatal intestine. J. Ped. Gastroenterol. Nutr., 2, 204-228.

MEINZER H. P., SANDBLAD B., 1985. A simulation model for studies of intestinal cell dynamics. Comp. Meth. Prog. Biomed., 21, 89-98.

TRAHAIR J. F., SILVER M., ROBINSON P. M., 1984. The development of the late-term ovine fetal small intestine and the effects of adrenalectomy. Can. J. anim. Sci., 64 (Supp), 259-260.

TRAHAIR J. F., ROBINSON P. M., 1986a. The development of the ovine small intestine. Anat. Rec., 214, 294-303.

TRAHAIR J. F., ROBINSON P. M., 1986b. Perinatal development of the small intestine of the sheep. Reprod. Nutr. Dév., 26, 1255-1263.

TRAHAIR J. F., AVILA C. G., ROBINSON P. M., 1986a. Growth of the fetal sheep small intestine. Growth, 50, 201-216.

TRAHAIR J. F., HARDING R., BOCKING A. D., SILVER M., ROBINSON P. M., 1986b. Role of ingestion in the development of the sheep small intestine. Q. J. exp. Physiol., 71, 99-104. 
TRAHAIR J. F., PERRY R. A., SILVER M., ROBINSON P. M., 1986c. Enterocyte migration in the fetal sheep small intestine. Biol. Neonate, 50, 214-220.

TRAHAIR J. F., PERRY R. A., SILVER M., ROBINSON P. M., 1986d. The autoradiographic localization of $\left({ }^{3} \mathrm{H}\right)$ thymidine incorporation in the fetal sheep small intestine. J. Ped. Gastroenterol. Nutr., 5, 648-654.

TRAHAIR J. F., PERRY R. A., SILVER M., ROBINSON P. M., 1987a. Studies on the maturation of the small intestine in the fetal sheep. I. The effects of bilateral adrenalectomy. $Q$. J. exp. Physiol., 72, 61-69.

TRAHAIR J. F., PERRY R. A., SILVER M., ROBINSON P. M., 1987b. Studies on the maturation of the small intestine in the fetal sheep. II. The effects of exogenous cortisol. $Q$. J. exp. Physiol., 72, 71-79. 